\title{
PRESnovo: Prescreening Prior to de novo Sequencing to Improve Accuracy and Sensitivity of Neuropeptide Identification
}

\author{
Kellen DeLaney ${ }^{1, \#}$, Weifeng Cao ${ }^{1, \#}$, Yadi Ma², Mingming Ma ${ }^{3}$, Yuzhuo Zhang ${ }^{1}$, Lingjun $\mathrm{Li}^{1,3,{ }^{*}}$ \\ ${ }^{1}$ Department of Chemistry, University of Wisconsin-Madison, 777 Highland Ave., Madison, WI \\ 53705 \\ 2Department of Computer Sciences and University of Wisconsin-Madison, 777 Highland Ave., \\ Madison, WI 53705 \\ ${ }^{3}$ School of Pharmacy, University of Wisconsin-Madison, 777 Highland Ave., Madison, WI 53705
}

\section{Abstract}

\begin{abstract}
Identification of peptides in species lacking fully-sequenced genomes is challenging due to the lack of prior knowledge. De novo sequencing is the method of choice, but its performance is less than satisfactory due to algorithmic bias and interference in complex MS/MS spectra. The task becomes even more challenging for endogenous peptides that do not involve an enzymatic digestion step, such as neuropeptides. However, many neuropeptides possess common sequence motifs that are conserved across members of the same family. Taking advantage of this feature to improve de novo sequencing of neuropeptides, we have developed a method named PRESnovo (prescreening precursors prior to de novo sequencing) to predict the motif from a MS/MS spectrum. A neuropeptide sequence is broken into a motif with conserved amino acid residues and the remaining partial sequence. By searching against a predefined motif database constructed from known homologous sequences, PRESnovo assigns the most probable motif to each precursor via a sophisticated scoring function. Performance analysis was conducted with 15 neuropeptide standards, and 11 neuropeptides were correctly identified with PRESnovo compared to 1 identification by PEAKS only. We applied PRESnovo to assign motifs to peptide sequences in conjunction with PEAKS for assigning the rest of the peptide sequence in order to discover neuropeptides in tissue samples of green crab, $C$. maenas, and Jonah crab, $C$. borealis. Collectively, a large number of neuropeptides were identified, including 13 putative neuropeptides identified in green crab brain, 77 in Jonah crab brain, and 47 in Jonah crab sinus glands for the first time. This PRESnovo strategy greatly simplifies de novo sequencing and enhances the accuracy and sensitivity of neuropeptide identification when common motifs are present.
\end{abstract}

\section{Graphical Abstract}

\footnotetext{
*To whom correspondence should be addressed. Address reprint requests to Dr. Lingjun Li. Mailing Address: 5125 Rennebohm Hall, 777 Highland Avenue, Madison, WI 53706-2222. Phone: (608)265-8491, Fax: (608)262-5345. lingjun.li@wisc.edu.

\#These authors contributed equally to this work.

Supporting Material Available

Experimental details for crustacean tissue collection, preparation, and MS analysis, table of peptide standards used for performance analysis, and MS/MS spectra of all putative novel neuropeptides are included in the supporting material.
} 


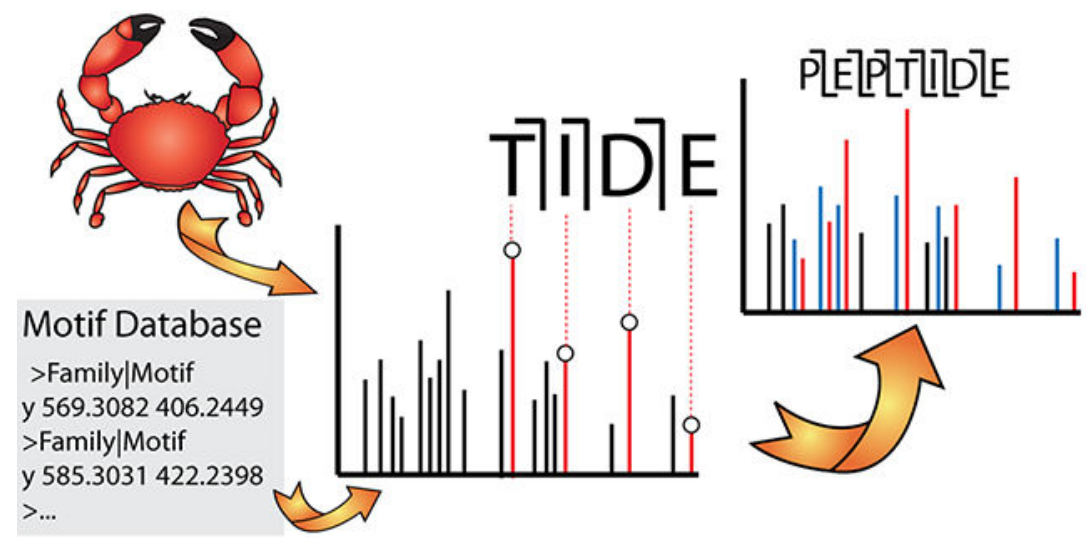

\section{Keywords}

PRESnovo; de novo sequencing; tandem mass spectrometry; neuropeptide; peptide identification; motif

\section{Introduction}

With the advancement of high-throughput mass spectrometry (MS), shotgun proteomics has been employed as the major tool for performing large-scale analysis of biological samples. With current MS instruments and workflows, thousands of MS and MS/MS spectra are produced from a single analysis [1-3]. With the large numbers of spectra being generated, traditional manual analysis is no longer feasible, and numerous data analysis strategies have been developed to identify proteins from the high volume of MS/MS spectra. The methods of choice for annotating these spectra mainly include spectral matching, database searching, and de novo sequencing. Spectral matching can be performed with a variety of software platforms, including SpectraST [4], X1Hunter [5], and Bibliospec [6]. However, this method of analysis requires the generation of spectral libraries, which can be time consuming and costly. Database searching employs search engines such as Mascot, SEQUEST, OMSSA, MSFragger and X!Tandem [7-11] to interpret tandem MS spectra by scoring the similarities between the experimental and theoretical spectra generated through in silico prediction. The matches are then ranked such that the match with the highest score is the best predicted peptide spectrum match. While this method has proven to be highly effective for large-scale identifications, it requires prior knowledge of the sequences of peptides in the sample, typically through the use of genomic data. This limits its applicability to organisms with a fully-sequenced genome.

For those species without a fully-sequenced genome, no protein database is available, and so de novo sequencing is the main approach employed for peptide identification. With de novo sequencing, peptide sequences are derived from the masses of their fragment ions as shown in a MS/MS spectrum. When performing de novo sequencing, no protein sequence database is used for reference, and so no prior knowledge is required of peptides in the sample. A number of algorithms and software packages have been developed recently for de novo peptide sequencing [12-15]. Most software use "spectral graph" or "probabilistic model" to 
interpret MS/MS spectra. A spectral graph is constructed from a MS/MS spectrum in which nodes represent fragment peaks and two nodes are connected by an edge if the mass difference between these two nodes matches a known amino acid residue. The algorithm tries to find the longest possible path of connected edges from the $\mathrm{N}$-terminus to the $\mathrm{C}$ terminus in order to determine the combination of amino acids that best represents the peptide sequence. However, any incompleteness of fragmentation can cause gaps which disconnect the longest path from $\mathrm{N}$ - to C-termini. In some cases, the longest path fails to represent the correct sequence or partial sequences due to interfering fragments. Instead of constructing spectral graphs, some algorithms such as PEAKS [15] compute peptide sequences among all possible amino acid combinations and then map these sequences directly onto each MS/MS spectrum to find the best sequence match, which improves the likelihood of a correct sequence assignment despite interfering ions. While this method is more computationally expensive, dynamic programming is always employed to increase the computing efficiency. As a result, this method has been employed successfully for numerous de novo sequencing methods. However, in comparison to the database search strategy, the accuracy and sensitivity of de novo sequencing are far less satisfactory [16]. The combination of database searching and de novo sequencing to some extent improves the accuracy of prediction $[16,17]$. Although these hybrid methods enhance peptide prediction, they require protein databases available for the species of interest. For species without available genomes, improving peptide identification remains an unmet challenge.

One example of a group of species without a complete genome is crustaceans, which are important model organisms for studying dynamic neural networks and neuromodulation. Neuropeptides, or short endogenous peptides involved in neuronal signaling, are an important class of molecules related to this system. Much effort has been placed on characterizing the neuropeptides involved in these signaling pathways with MS [18-24] and in silico prediction [25]. However, this class of molecules is particularly challenging to study because their workflow does not involve a digestion step [26]. With tryptic digests from proteins, the search space is able to be reduced based on how trypsin digests the proteins with well-defined amino acid residue at the carboxyl-end of resulting tryptic peptides. With neuropeptides, no enzymatic digestion parameters can be used to reduce the search space. However, highly-conserved peptide sequences like neuropeptides share conserved motifs, which can aid de novo sequencing. Herein, we focus on interpreting a part of a tandem MS spectrum to extract the conserved sequence motif instead of sequencing the entire MS/MS fragmentation spectrum. The determination of a motif will simplify de novo sequencing of the rest of the sequence and increase the accuracy of peptide identification. In order to determine the neuropeptide sequence motif, a database search method is employed similar to commonly-used methods previously described. First, motifs are derived from known peptide sequences from homologous species. Second, theoretical in silico fragmentation is performed for these motifs. The resulting b-and $y$ - ions as well as their neutral loss fragments together with the corresponding motif are used to construct a motif database. This database is then searched by inputting experimental fragments to find the best matched motif for each precursor. A sophisticated scoring function, based on the sum of ratios of lengths of fragments to total motif lengths, ensures the correct assignment of motif to a given precursor. This strategy, named PRESnovo, simplifies the subsequent de novo sequencing 
step and increases the accuracy and sensitivity of peptide identifications by performing a preprocessing function prior to de novo sequencing.

\section{Methods}

\section{Construction of Motif Database.}

A motif database is required to run PRESnovo. Here, motif refers to a representation of the similarity of different sequences in the same peptide family. For accurate results, it is recommended that all possible motifs for the peptides of interest are included. In this study, previously known neuropeptides from invertebrate species, mainly crustaceans, were collected from public databases including Uniprot knowledgebase and publications [25, 27-29]. In order to estimate the false positive rate, some vertebrate motifs were also included as decoy motifs because these motifs were not observed in crustacean neuropeptides. As the targeted neuropeptide sequences in most cases contain fewer than 20 amino acid residues, longer sequences such as proteins or receptors were excluded from the list. Figure 1 shows how a motif database is constructed. The known neuropeptides collected from the various sources were clustered according to their family names followed by a multiple alignment procedure with ClustALW2 (http://www.ebi.ac.uk/Tools/msa/clustalw2/) for each family. Afterwards, the most aligned region was truncated to extract motifs with WebLogo3 (http:// weblogo.threeplusone.com/). Longer peptides whose motifs were not easily determined were removed from the list, such as Bursicon, crustacean hyperglycemic hormone $(\mathrm{CHH})$, molt inhibiting hormone (MIH), etc. When using WebLogo3, multiple motifs were adopted to represent each family. For example, all $5 \mathrm{C}$-terminal motifs, YAFGL, YDFGL, YNFGL, YEFGL, and YSFGL, were used to represent allatostatin A-type (AST-A) peptides.

The PRESnovo method works by mapping tandem MS spectra onto a home-built motif database in order to find the best suitable motif for each precursor. The practical implementation is to compare the experimental fragments associated with a precursor to those theoretical fragments associated with a motif. Therefore, a list of theoretical fragments must be created for each motif. The extracted motifs were in silico fragmented by MSProduct (http://prospector.ucsf.edu/prospector/cgi-bin/msform.cgi?form=msproduct), and the resulting $b$ ion set (including $b$ ions and neutral losses, $b-\mathrm{H}_{2} \mathrm{O}$ and $\mathrm{b}-\mathrm{NH}_{3}$ ) were adopted as the theoretical fragments for $\mathrm{N}$-terminal motifs while y ion set (including y ions and neutral losses, $\mathrm{y}-\mathrm{H}_{2} \mathrm{O}$ and $\mathrm{y}-\mathrm{NH}_{3}$ ) were adopted as the theoretical fragments for C-terminal motif. Post-translational modifications (PTM) were also included when fragmenting these motifs. For example, for motif YXFGLamide, C-terminal amidation was considered for the production of theoretical fragments. These were selected based on common PTMs observed for neuropeptide families [27, 30].

We used these extracted motifs and the associated theoretical fragments to construct our motif database (see supplemental file) in which 87 motifs covering 25 families were compiled for crustacean neuropeptides ( 2 families of 7 mammalian neuropeptides (Angiotensinogen (5) and Arg_vasopressin (2) were also included for test only, to be used as decoys to assess the false positive rate). The distribution of the motifs is shown in Figure 2. 


\section{Scoring Function and Motif Assignment.}

Accurately assigning a motif to a given precursor is crucial. A well-defined scoring function can ensure the unbiased assignment of a motif in most cases. As such, a score is needed to evaluate the comparison between experimental and theoretical fragments within PRESnovo. Several considerations must be taken to generate a scoring function. These factors include significance of different-length theoretical fragments, the number of matches between experimental and theoretical fragments, and the percentage of the total number of experimental fragments with respect to the total number of theoretical fragments. We first define the score of a theoretical fragment via dividing the length of fragment by the total length of the motif. This definition is suitable because the significance of longer fragments is higher than that of shorter fragments [31]. This score definition is also beneficial to the interpretation of non-informative tandem MS spectra because any high-scoring longer fragments can ensure a reliable motif assignment without consideration of gaps. After computing scores for fragments, these fragment scores were used to evaluate the motif assignment. Given that the more theoretical fragments are matched by experimental fragments the more reliable the corresponding motif assignment is, the score for a motif assignment is defined by the following formula:

$$
S\left(P\left(\vec{F}_{E}\right) \sim M\left(\vec{F}_{T}\right)\right)=\frac{\sum S_{E}\left(\vec{F}_{E} \mid M\left(\vec{F}_{T}\right)\right)}{\sum S_{T}\left(\vec{F}_{T} \mid M\left(\vec{F}_{T}\right)\right)}
$$

$S\left(P\left(\vec{F}_{E}\right) \sim M\left(\vec{F}_{T}\right)\right)$ is the score for motif $\mathrm{M}\left(M\left(\vec{F}_{T}\right)\right)$ assigned to a precursor $\left(P\left(\vec{F}_{E}\right)\right)$, $\sum S_{E}\left(\vec{F}_{E} \mid M\left(\vec{F}_{T}\right)\right)$ is the sum of the scores of all matched experimental fragments while $\sum S_{T}\left(\vec{F}_{T} \mid M\left(\vec{F}_{T}\right)\right)$ is the sum of the scores of all theoretical fragments. In our motif database, the scores of fragments were calculated in advance and stored along with motifs. The neutral loss fragments share the same score as the associated b or $\mathrm{y}$ ions.

The workflow for using PRESnovo to assign the best matched motif to a given precursor is shown in Figure 3. The user-defined mass error tolerance was set to 0.5 Da for QTOF data and $0.02 \mathrm{Da}$ for Orbitrap data for both precursor and fragments. The experimental fragments were compared to the theoretical fragments associated with each motif and the matched pairs were stored. If a neutral loss ion pair and the corresponding $\mathrm{b}$ or $\mathrm{y}$ ion pair were both found, only one pair was kept for the following calculation. In the list of matched fragment pairs, all the matched theoretical fragment scores were used to calculate the score of each motif assignment. As a result, for a given precursor, all motifs were tentatively assigned to it with calculated scores. These motifs were then ranked in descending order based on the score for each motif assignment and the first five ranked motifs were reported.

\section{NanoLC-ESI-QTOF Analysis for Peptide Standards and Tissue Sample.}

A peptide standard mixture containing 15 neuropeptides (Supplemental Table S1) was subjected to nano-LC-ESI-QTOF (Waters Corp., Milford, MA) and the resulting MS data were used to test the performance of PRESnovo. Furthermore, PRESnovo was used for real tissue sample to identify endogenous neuropeptides. Tissue samples were extracted from the 
brain of European green crabs, $C$. maenas and brain and sinus glands of Jonah crabs, $C$. borealis. Green crab tissue was offline HPLC fractionated, and the collected fractions were analyzed on a nano-LC-ESI-QTOF (Waters Corp., Milford, MA). The Jonah crab tissue was analyzed on a nano-LC-ESI Q Exactive Orbitrap mass spectrometer (Thermo Scientific, Bremen, Germany). The details about experimental protocols including animal dissection, tissue extraction, offline HPLC fractionation and MS analysis can be found in the Supporting Information and followed those previously described [32]. After MS analysis, the QTOF raw data were converted into pkl formatted data with ProteinLynx (Waters Corp., Milford, MA). Parameters for ProteinLynx were set with default settings except noise reduction threshold at $10 \%$. The Orbitrap raw data was converted into mzXML format using MSConvert with default settings [33].

\section{De novo Sequencing with the Aid of PRESnovo.}

The resulting pkl and mzXML files were used as input to PRESnovo. The current version of PRESnovo supports pkl and mzXML formats. Parsing of mzXML data was performed with jmzReader [34]. Other data formats need to be converted into one of these two formats. Mass tolerances for both precursor and fragments were set to 0.5 Da for QTOF data and 0.02 Da for Orbitrap data. PRESnovo outputs a .csv file in which each precursor is assigned five motifs as the default setting according to a descending order of score. The number of motif assignments can be changed by the user. The scored fragments associated with each motif are also included in the output. By setting a motif score threshold, the user can filter out lowconfidence motif assignments. Once a motif is obtained, the rest of the sequence can be determined by either manual sequencing or PEAKS. Given that PEAKS can report highconfidence sequence tags with individual positional confidence scores [15], it is very useful to combine PEAKS and PRESnovo together to sequence a peptide.

As a comparison, raw MS/MS data was also processed with PEAKS. The raw data were directly loaded into PEAKS (PEAKS 7, Bioinformatics Solutions Inc., Waterloo, ON) for de novo sequencing. The setting for PEAKS were as follows: mass error tolerances for both precursor and fragments $0.5 \mathrm{Da}$ for QTOF data and 0.02 Da for Orbitrap data, no enzyme digestion, and pyro-glutamine (pQ), pyro-glutamic acid $(\mathrm{pE})$, oxidation of methionine, and C-terminal amidation as variable PTMs.

\section{Results and Discussion Performance of PRESnovo.}

In order to evaluate the performance of PRESnovo, a standard mixture comprised of 15 peptides was analyzed with LC-MS/MS on a Waters QTOF instrument. The data were processed with both PRESnovo and PEAKS de novo sequencing to compare performance. As five predictions were output from both software packages, it was important to differentiate which was the most suitable. The predicted sequences from each software were compared to the actual sequences of the standards. Interestingly, in most cases, the first prediction was the best one in the PRESnovo results. In the PEAKS results, this was not always the case, as other sequence predictions rather than the first one were the best prediction for some peptides. Table 1 summarizes the results obtained from PRESnovo and 
PEAKS. Five output sequences are provided from both software, and the sequence matching the standard the closest is displayed. As shown, 11 out of 15 peptides were predicted correctly by PRESnovo while only 1 was computed correctly by PEAKS with at least six consecutively correct residues. The 11 peptides identified by PRESnovo produced doublycharged precursors leading to an almost even number of $\mathrm{b}$ and $\mathrm{y}$ ions, which facilitated the detection of fragments associated with their motifs by PRESnovo. Two examples are shown in Figure 4, from which it can be seen that almost all motif-related fragments were produced, although some of them were at low intensities. Consequently, two motifs were confidently assigned to the precursors, respectively. However, PEAKS lacks specificity for identification of these endogenous peptides because PEAKS is originally designed for general use in bottom-up proteomics where tryptic peptides are the main targets. With tryptic peptides, certain patterns exist that inform the resulting de novo sequences obtained. As a result, PEAKS by itself is not optimal for non-tryptic peptide prediction [15]. Because PRESnovo is designed to recognize patterns specific to endogenous neuropeptides, it provides improved accuracy in sequencing these signaling peptides when used in conjunction with PEAKS.

The 4 peptides not identified correctly by PRESnovo fall into two categories: AST-A peptides (GDGRLYAFGLa and APSGAQRLYGFGLa) and disulfide bond bridging peptides (PFCNAFTGCa and CYFQNCPRGa). AST-A peptides are generally ionized as singly charged precursors which tend to produce predominantly N-terminal (primarily b-series) fragments. These fragments ( $\mathrm{a} / \mathrm{b} / \mathrm{c}$ ions) dominate the MS/MS spectrum, as shown in Figure 5A. However, the characteristic motif of AST-A peptides, YXFGLamide (X is a variable residue), is located at the $\mathrm{C}$-terminus, which causes the motif database to deduce $\mathrm{y}$-series fragments from this motif. As a result, the mismatch between the experimental b-series fragments and in silico y-series fragments leads to misidentification of these peptides. Although this demonstrates a limitation of PRESnovo's predicting power, it is not difficult to manually sequence AST-A peptides with the aid of PEAKS, given that most peptides belonging to this family have a simple pattern of b-ions dominating fragmentation. Disulfide bond bridging peptides are prone to producing complicated internal fragments that suppress the production of $b / y$ ions (Figure $5 \mathrm{~B}$ ). As a result, not enough motif-associated b/y ions are available for PRESnovo to determine the motif for the precursor. While the inability to predict disulfide bond bridging peptide sequences is a limitation of PRESnovo, the same is true across many de novo sequencing software. Disulfide bond bridging peptides are relatively uncommon amongst neuropeptides, and only 4 possible sequences with a characteristic motif are present in the crustacean neuropeptide database. Therefore, this limitation is not expected to substantially impede the identification of crustacean neuropeptides.

\section{The Factors Impacting on the Performance of PRESnovo.}

The performance of PRESnovo is impacted mainly by the motif database being searched and the quality of tandem MS spectra being queried. The construction of a motif database is crucial to PRESnovo, as accurate, detailed compilation of motifs improves the likelihood of confident identifications being made. A motif database consists of two parts: a string of amino acids comprising each motif and its associated fragments. Motifs are generally 
collected from known peptide sequences present in homologous species. There is a tradeoff between the number of motifs incorporated in a motif database and the prediction power of PRESnovo. If too few motifs are included such that all forms of a neuropeptide motif are not sufficiently represented, the search may return results with low specificity or inaccurate identifications. Conversely, having an excess number of motifs included in the database inflates the false positive rate and decreases the sensitivity of the assignment [35]. In order to maximize the detection of neuropeptides in tissue samples, a motif library containing at least 80 motifs is satisfactory, as indicated in Figure S1a. To avoid these issues, only biologicallyrelated species should be considered when extracting motifs for a species of interest. For example, in this study, motifs were only extracted from known peptide sequences in other crustacean species. If the interest is in peptide identifications from a vertebrate species such as human or mouse, a vertebrate peptide motif database can be created specifically for the species of interest that only includes those from similar species. In this way, effort can be made to exclude interference from other motifs that are not likely to be present in the species of interest. Another possible solution is to use long motifs, which would reduce the likelihood of false positive prediction and would also simplify the subsequent de novo sequencing. In silico fragments associated with motifs also impact on the performance of PRESnovo. In our current motif database, only b and y series ions (i.e., b, y, and neutral loss ions) are included for each motif while no $\mathrm{a} / \mathrm{c}$ or $\mathrm{x} / \mathrm{z}$ ions are considered. The reason for this specification is that $\mathrm{b}$ and $\mathrm{y}$ ions are sufficient for determining a motif even though some of them may have low abundance in some cases.

The quality of tandem MS spectra also has significant impact on the performance of PRESnovo. Different from many automated de novo algorithms, PRESnovo can predict correct motifs for relatively low-quality MS/MS spectra provided that enough motifassociated fragments are present in the spectra. However, in the case of processing less informative spectra, if the experimental fragments associated with motif are insufficient or high-score fragments (i.e. large fragments) are missed, PRESnovo will report lowconfidence motifs, resulting in high false negative rate for peptide prediction. On the other hand, if a tandem MS spectrum contains too much noise and these interferences are not effectively removed, it will lead to the wrong motif assignment and thus increase the false positive rate [36-38]. Therefore, an efficient and effective preprocessing algorithm is needed to clean up tandem MS spectra. In this study we used ProteinLynx (Waters Co.) to remove noise or background signals from QTOF data prior to processing. ProteinLynx adopts Savitzky-Golay method to smooth the data and thus ensure fewer interfering signals are contained in the final pkl data files. While the quality of MS/MS spectra is important, the mass accuracy of MS/MS spectra does not appear to substantially impact the performance of PRESnovo, as shown in Figure S1b, where the search was run with alternating mass error tolerances and, except for very high mass errors (e.g. greater than 1,000 ppm), the results remained consistent.

\section{Application of PRESnovo in conjunction with PEAKS to identify neuropeptides in C. maenas and $\mathrm{C}$. borealis.}

While PRESnovo accurately predicts the sequence motif of a neuropeptide, its use in conjunction with PEAKS de novo software enables improved detection of neuropeptides 
present in real biological samples. An important characteristic of PEAKS is its ability to report the positional confidence for each amino acid in the predicted sequence [11]. This feature can be used to identify the rest of the sequence after PRESnovo predicts the motif. For instance, peptide TNFAFSPRLa shown in Figure 2 was predicted with high confidence to possess the motif of FSPRLa (score: 0.93) by PRESnovo. Meanwhile, PEAKS reports a confident N-terminal sequence tag TNFAFSP (as in Table 1) for the same peptide. By combining these two predictions, one can easily determine the sequence with manual verification.

PRESnovo and PEAKS were employed collectively to identify neuropeptides in tissue samples of green crab, $C$. maenas, and Jonah crab, $C$. borealis. These animals were chosen because they are well-characterized model organisms whose nervous systems have been previously studied using electrophysiology and immunohistochemistry [39-42]. However, while their dynamic neural networks are well-understood, there is currently no fullysequenced genome available for either species, and so their neuropeptidomes are not yet fully characterized. Furthermore, with the inherent difficulties associated with MS characterization of neuropeptides, even detecting known neuropeptides remains challenging. To address these challenges and uncover more of the neuropeptides underlying neural modulation in these organisms, PRESnovo was employed in conjunction with PEAKS. First, PRESnovo was used to identify a motif for each precursor. The motif score threshold was set to 0.60 to filter out low-scoring motif assignments and the corresponding precursors. For high-score precursors, the PRESnovo results were compared to their corresponding PEAKS predictions. Manual sequencing was then used to combine this information and determine the final sequence for each precursor.

Brain extract from green crab was analyzed on a Waters QTOF instrument and preprocessed with ProteinLynx prior to PRESnovo analysis. The resulting data included 77 neuropeptides, summarized in Table 2, of which 13 sequences are putative neuropeptides that have never before been identified in green crab [43]. Of the 13 novel sequences, 7 of them have previously been identified in other invertebrate species, such as Callinectes sapidus and Homarus americanus, and all were only identified with the assistance of PRESnovo. Both brain and sinus gland tissue extracts from Jonah crab were analyzed on a Thermo Q Exactive Orbitrap instrument, and the raw files were converted to the open-source mzXML format. After analysis with PRESnovo and PEAKS, 100 neuropeptides were identified in the brain sample, 77 of these being putative novel neuropeptides never before identified in previous literature. The repeatability across technical replicates and overlap between biological replicates from distinct brain samples are shown in Figure S2. A total of 76 neuropeptides were identified in the sinus glad extract, with 47 of these sequences being putative novel neuropeptides not previously identified in any species. Table 3 summarizes the neuropeptides detected in Jonah crab that match the crustacean database, while Table 4 lists the putative novel neuropeptides identified in Jonah crab, 24 of which were only identified with the assistance of PRESnovo. Figures $6 \mathrm{a}$ and $6 \mathrm{~b}$ show MS/MS spectra of novel neuropeptides identified in brain and sinus gland tissue, respectively. Figures S3 -S5 show the MS/MS spectra of all novel neuropeptides identified. As can be seen, PRESnovo predicted the characteristic sequence motif that led to the full neuropeptide sequence shown. Figure $6 \mathrm{c}$ shows a neuropeptide identified that is present in the crustacean database but was 
incorrectly assigned by PEAKS, demonstrating the improvement in identification afforded by PRESnovo pre-screening. The originally-predicted sequence in PEAKS scrambled the last three amino acids, but PRESnovo was able to assign them based on mapping the fragment ions to a common sequence motif. This example demonstrates the improved accuracy offered by combining PRESnovo with PEAKS for de novo sequencing, as identifying fragment ions characteristic of neuropeptide sequence motifs increases the likelihood of correct identifications.

Of the neuropeptides identified in the two species, the most common families were AST-A, FMRFamide-related peptide (FaRP), RYamide, orcokinin, tachykinin, and pyrokinin. AST-A and AST-B neuropeptides are distributed throughout the nervous and neuroendocrine system of crustaceans and have been found to be inhibitors of neuromodulation [44, 45]. Several novel peptides belonging to these families were identified in both the brain and sinus glands, indicating that these peptides may also exhibit inhibitory effects. FaRP neuropeptides have been found to have a variety of functions within the nervous and neuroendocrine system, including as autocrines, paracrines, and circulating hormones [46-48]. Therefore, it is expected that these neuropeptides would be identified in both the sinus glands where they may be released as circulating hormones and in the brain, where they may serve a more local function within the neuropil. While there have not been many studies on the function of pyrokinins in crustaceans, they were found to have an effect on the gastric mill [49]. As the brain sends neuronal projection to innervate the stomach movement of the crab, pyrokinin neuropeptides were mostly identified in the brain tissue and the putatively identified novel pyrokinin peptides may also have a role in gastric activity. Tachykinin and orcokinin peptides are also more prominent in the stomatogastric nervous system, with a variety of functions including hindgut contractions [50-52]. In this study, putative novel tachykinin and orcokinin peptides were identified in the brain that may also have a role in modulating some stomach activity. Additionally, 3 tachykinin peptides were identified in the sinus gland, indicating that they may have a different modulatory role. Putative novel RYamide neuropeptides were identified in the brain and sinus glands as well. The biological activity of RYamides is not fully understood, but they have been previously identified in neuroendocrine tissue and central neuropil, suggesting functions both locally and as circulating hormones $[53,54]$.

Follow-up experiments will need to be performed in order to confirm the putative peptide identifications and determine their biological activities. However, these results demonstrate the great potential PRESnovo has for both facilitating the discovery of novel neuropeptides and improving detection coverage of the crustacean neuropeptidome identified in analyses. This application provided here indicates that PRESnovo can greatly improve the discovery of neuropeptides across a variety of other species and indicates potential for improving identification of other endogenous peptides across a variety of other sample types, provided that commonly-shared sequence motifs exist.

\section{Conclusions}

In this work, a prescreening strategy, namely PRESnovo, was developed to improve the accuracy, specificity and sensitivity of peptide identification. In conjunction with de novo 
sequencing algorithms such as PEAKS, this method is powerful for identification of highly conserved peptides such as neuropeptides. The strategy we proposed in this manuscript can be easily extended to other species of interest, provided that a well-constructed motif database is obtained. Future directions may include incorporation of more sophisticated algorithms for sequencing disulfide bond bridging peptides and peptides with motifs that are difficult to detect, such as AST-A. The software and motif database used in this work can be freely downloaded via the following link: https://www.lilabs.org/resources.

\section{Supplementary Material}

Refer to Web version on PubMed Central for supplementary material.

\section{Acknowledgements}

This work was supported by a National Science Foundation grant (CHE-1710140) and the National Institutes of Health (NIH) through grant 1R01DK071801. The Orbitrap instruments were purchased through the support of an NIH shared instrument grant (NIH-NCRR S10RR029531). K.D. acknowledges a predoctoral fellowship supported by the National Institutes of Health-General Medical Sciences F31 National Research Service Award (1F31GM126870-01A1) for funding. LL acknowledges a Vilas Distinguished Achievement Professorship and Charles Melbourne Johnson Professorship with funding provided by the Wisconsin Alumni Research Foundation and University of Wisconsin-Madison School of Pharmacy.

\section{Abbreviations:}

AKH/RPCH Adipokinetic hormone/red pigment concentrating hormone

AST-A Allatostatin A

AST-B Allatostatin B

AVP Arginine vasopressin

CCAP Crustacean cardioactive peptide

FaLP FMRFamide-related peptide

\section{References}

1. Hunt DF, Michel H, Dickinson TA, Shabanowitz J, Cox AL, Sakaguchi K, Appella E, Grey HM, Sette A: Peptides presented to the immune system by the murine class II major histocompatibility complex molecule I-Ad. Science. 256, 1817-1820 (1992) [PubMed: 1319610]

2. Wolters DA, Washburn MP, Yates JR 3rd: An automated multidimensional protein identification technology for shotgun proteomics. Anal Chem. 73, 5683-5690 (2001) [PubMed: 11774908]

3. Foster LJ, de Hoog CL, Zhang Y, Xie X, Mootha VK, Mann M: A mammalian organelle map by protein correlation profiling. Cell. 125, 187-199 (2006) [PubMed: 16615899]

4. Lam H, Deutsch EW, Eddes JS, Eng JK, King N, Stein SE, Aebersold R: Development and validation of a spectral library searching method for peptide identification from MS/MS. Proteomics. 7, 655-667 (2007) [PubMed: 17295354]

5. Craig R, Cortens JC, Fenyo D, Beavis RC: Using annotated peptide mass spectrum libraries for protein identification. J Proteome Res. 5, 1843-1849 (2006) [PubMed: 16889405]

6. Frewen BE, Merrihew GE, Wu CC, Noble WS, MacCoss MJ: Analysis of peptide MS/MS spectra from large-scale proteomics experiments using spectrum libraries. Anal Chem. 78, 5678-5684 (2006) [PubMed: 16906711] 
7. Eng JK, Mccormack AL, Yates JR: An Approach to Correlate Tandem Mass-Spectral Data of Peptides with Amino-Acid-Sequences in a Protein Database. J Am Soc Mass Spectr. 5, 976-989 (1994)

8. Perkins DN, Pappin DJ, Creasy DM, Cottrell JS: Probability-based protein identification by searching sequence databases using mass spectrometry data. Electrophoresis. 20, 3551-3567 (1999) [PubMed: 10612281]

9. Craig R, Beavis RC: TANDEM: matching proteins with tandem mass spectra. Bioinformatics. 20, 1466-1467 (2004) [PubMed: 14976030]

10. Geer LY, Markey SP, Kowalak JA, Wagner L, Xu M, Maynard DM, Yang X, Shi W, Bryant SH: Open mass spectrometry search algorithm. J Proteome Res. 3, 958-964 (2004) [PubMed: 15473683]

11. Kong AT, Leprevost FV, Avtonomov DM, Mellacheruvu D, Nesvizhskii AI: MSFragger: ultrafast and comprehensive peptide identification in mass spectrometry-based proteomics. Nat Methods. 14, 513-520 (2017) [PubMed: 28394336]

12. Taylor JA, Johnson RS: Sequence database searches via de novo peptide sequencing by tandem mass spectrometry. Rapid Commun Mass Spectrom. 11, 1067-1075 (1997) [PubMed: 9204580]

13. Fischer B, Roth V, Roos F, Grossmann J, Baginsky S, Widmayer P, Gruissem W, Buhmann JM: NovoHMM: a hidden Markov model for de novo peptide sequencing. Anal Chem. 77, 7265-7273 (2005) [PubMed: 16285674]

14. Frank A, Pevzner P: PepNovo: de novo peptide sequencing via probabilistic network modeling. Anal Chem. 77, 964-973 (2005) [PubMed: 15858974]

15. Ma B, Zhang K, Hendrie C, Liang C, Li M, Doherty-Kirby A, Lajoie G: PEAKS: powerful software for peptide de novo sequencing by tandem mass spectrometry. Rapid Commun Mass Spectrom. 17, 2337-2342 (2003) [PubMed: 14558135]

16. Frank AM, Savitski MM, Nielsen ML, Zubarev RA, Pevzner PA: De novo peptide sequencing and identification with precision mass spectrometry. J Proteome Res. 6, 114-123 (2007) [PubMed: 17203955]

17. Kim S, Gupta N, Bandeira N, Pevzner PA: Spectral dictionaries: Integrating de novo peptide sequencing with database search of tandem mass spectra. Mol Cell Proteomics. 8, 53-69 (2009) [PubMed: 18703573]

18. Zhang Y, DeLaney K, Hui L, Wang J, Sturm RM, Li L: A Multifaceted Mass Spectrometric Method to Probe Feeding Related Neuropeptide Changes in Callinectes sapidus and Carcinus maenas. J Am Soc Mass Spectrom. 29, 948-960 (2018) [PubMed: 29435768]

19. DeLaney K, Li L: Data Independent Acquisition Mass Spectrometry Method for Improved Neuropeptidomic Coverage in Crustacean Neural Tissue Extracts. Anal Chem. 91, 5150-5158 (2019) [PubMed: 30888792]

20. DeLaney K, Li L: Capillary electrophoresis coupled to MALDI mass spectrometry imaging with large volume sample stacking injection for improved coverage of C. borealis neuropeptidome. Analyst. 145, 61-69 (2019) [PubMed: 31723949]

21. Liu Y, Buchberger AR, DeLaney K, Li Z, Li L: Multifaceted Mass Spectrometric Investigation of Neuropeptide Changes in Atlantic Blue Crab, Callinectes sapidus, in Response to Low pH Stress. J Proteome Res. 18, 2759-2770 (2019) [PubMed: 31132273]

22. Ma MM, Bors EK, Dickinson ES, Kwiatkowski MA, Sousa GL, Henry RP, Smith CM, Towle DW, Christie AE, Li LJ: Characterization of the Carcinus maenas neuropeptidome by mass spectrometry and functional genomics. General and Comparative Endocrinology. 161, 320-334 (2009) [PubMed: 19523386]

23. Hui LM, D'Andrea BT, Jia CX, Liang ZD, Christie AE, Li LJ: Mass spectrometric characterization of the neuropeptidome of the ghost crab Ocypode ceratophthalma (Brachyura, Ocypodidae). General and Comparative Endocrinology. 184, 22-34 (2013) [PubMed: 23298572]

24. Dickinson PS, Armstrong MK, Dickinson ES, Fernandez R, Miller A, Pong S, Powers BW, PupoWiss A, Stanhope ME, Walsh PJ, Wiwatpanit T, Christie AE: Three members of a peptide family are differentially distributed and elicit differential state-dependent responses in a pattern generatoreffector system. J Neurophysiol. 119, 1767-1781 (2018) [PubMed: 29384453] 
25. Christie AE, Pascual MG: Peptidergic signaling in the crab Cancer borealis: Tapping the power of transcriptomics for neuropeptidome expansion. Gen Comp Endocrinol. 237, 53-67 (2016) [PubMed: 27497705]

26. DeLaney K, Buchberger AR, Atkinson L, Grunder S, Mousley A, Li L: New techniques, applications and perspectives in neuropeptide research. J Exp Biol. 221, (2018)

27. Christie AE, Stemmler EA, Dickinson PS: Crustacean neuropeptides. Cell Mol Life Sci. 67, 41354169 (2010) [PubMed: 20725764]

28. Wang Y, Wang M, Yin S, Jang R, Wang J, Xue Z, Xu T: NeuroPep: a comprehensive resource of neuropeptides. Database (Oxford). 2015, bav038 (2015) [PubMed: 25931458]

29. Consortium U: UniProt: a worldwide hub of protein knowledge. Nucleic Acid Res. 47, D506D515 (2019) [PubMed: 30395287]

30. Hook V, Funkelstein L, Lu D, Bark S, Wegrzyn J, Hwang SR: Proteases for processing proneuropeptides into peptide neurotransmitters and hormones. Annu Rev Pharmacol Toxicol. 48, 393-423 (2008) [PubMed: 18184105]

31. Allet N, Barrillat N, Baussant T, Boiteau C, Botti P, Bougueleret L, Budin N, Canet D, Carraud S, Chiappe D, Christmann N, Colinge J, Cusin I, Dafflon N, Depresle B, Fasso I, Frauchiger P, Gaertner H, Gleizes A, Gonzalez-Couto E, Jeandenans C, Karmime A, Kowall T, Lagache S, Mahe E, Masselot A, Mattou H, Moniatte M, Niknejad A, Paolini M, Perret F, Pinaud N, Ranno F, Raimondi S, Reffas S, Regamey PO, Rey PA, Rodriguez-Tome P, Rose K, Rossellat G, Saudrais C, Schmidt C, Villain M, Zwahlen C: In vitro and in silico processes to identify differentially expressed proteins. Proteomics. 4, 2333-2351 (2004) [PubMed: 15274127]

32. DeLaney K, Buchberger A, Li L: Identification, Quantitation, and Imaging of the Crustacean Peptidome. Methods Mol Biol. 1719, 247-269 (2018) [PubMed: 29476517]

33. Adusumilli R, Mallick P: Data Conversion with ProteoWizard msConvert. Methods Mol Biol. 1550, 339-368 (2017) [PubMed: 28188540]

34. Griss J, Reisinger F, Hermjakob H, Vizcaino JA: jmzReader: A Java parser library to process and visualize multiple text and XML-based mass spectrometry data formats. Proteomics. 12, 795-798 (2012) [PubMed: 22539430]

35. Wang G, Wu WW, Zhang Z, Masilamani S, Shen R: Decoy Methods for Assessing False Positives and False Discovery Rates in Shotgun Proteomics. Anal Chem. 81, 146-159 (2009) [PubMed: 19061407]

36. Xu H, Freitas MA: A Dynamic Noise Level Algorithm for Spectral Screening of Peptide MS/MS Spectra. BMC Bioinformatics. 11, 1-8 (2010) [PubMed: 20043860]

37. Sadygov RG, Cociorva D, Yates J.R.r.: Large-scale database searching using tandem mass spectra: looking up the answer in the back of the book. Nat Methods. 1, 195-202 (2004) [PubMed: 15789030]

38. Zhang J, Gonzalez E, Hestilow T, Haskins W, Huang Y: Review of Peak Detection Algorithms in Liquid-Chromatography-Mass Spectrometry. Current Genomics. 10, 388-401 (2009) [PubMed: 20190954]

39. DeLaney K, Buchberger AR, Atkinson L, Grunder S, Mousley A, Li LJ: New techniques, applications and perspectives in neuropeptide research. Journal of Experimental Biology. 221, (2018)

40. Marder E, Gutierrez GJ, Nusbaum MP: Complicating connectomes: Electrical coupling creates parallel pathways and degenerate circuit mechanisms. Dev Neurobiol. 77, 597-609 (2017) [PubMed: 27314561]

41. Nusbaum MP, Blitz DM, Marder E: Functional consequences of neuropeptide and small-molecule co-transmission. Nat Rev Neurosci. 18, 389-403 (2017) [PubMed: 28592905]

42. White RS, Spencer RM, Nusbaum MP, Blitz DM: State-dependent sensorimotor gating in a rhythmic motor system. J Neurophysiol. 118, 2806-2818 (2017) [PubMed: 28814634]

43. Ma M, Bors EK, Dickinson ES, Kwiatkowski MA, Sousa GL, Henry RP, Smith CM, Towle DW, Christie AE, Li L: Characterization of the Carcinus maenas neuropeptidome by mass spectrometry and functional genomics. Gen Comp Endocrinol. 161, 320-334 (2009) [PubMed: 19523386] 
44. Skiebe P, Schneider H: Allatostatin peptides in the crab stomatogastric nervous system: inhibition of the pyloric motor pattern and distribution of allatostatin-like immunoreactivity. Journal of Experimental Biology. 194, 195-208 (1994) [PubMed: 7964402]

45. Jorge-Rivera J, Marder E: Allatostatin decreases stomatogastric neuromuscular transmission in the crab Cancer borealis. J Exp Biol. 200, 2937-2946 (1997) [PubMed: 9359878]

46. Dockray GJ: The expanding family of -RFamide peptides and their effects on feeding behaviour. Exp Physiol. 89, 229-235 (2004) [PubMed: 15123557]

47. Bechtold DA, Luckman SM: The role of RFamide peptides in feeding. J Endocrinol. 192, 3-15 (2007) [PubMed: 17210738]

48. Findeisen M, Rathmann D, Beck-Sickinger AG: RFamide Peptides: Structure, Function, Mechanisms and Pharmaceutical Potential. (2011)

49. Saideman SR, Ma M, Kutz-Naber KK, Cook A, Torfs P, Schoofs L, Li L, Nusbaum MP: Modulation of rhythmic motor activity by pyrokinin peptides. J Neurophysiol. 97, 579-595 (2007) [PubMed: 17065249]

50. Li L, Pulver SR, Kelley WP, Thirumalai V, Sweedler JV, Marder E: Orcokinin peptides in developing and adult crustacean stomatogastric nervous systems and pericardial organs. J Comp Neurol. 444, 227-244 (2002) [PubMed: 11840477]

51. Christie AE, Cashman CR, Stevens JS, Smith CM, Beale KM, Stemmler EA, Greenwood SJ, Towle DW, Dickinson PS: Identification and cardiotropic actions of brain/gut-derived tachykininrelated peptides (TRPs) from the American lobster Homarus americanus. Peptides. 29, 1909-1918 (2008) [PubMed: 18706463]

52. Sousa GL, Lenz PH, Hartline DK, Christie AE: Distribution of pigment dispersing hormone- and tachykinin-related peptides in the central nervous system of the copepod crustacean Calanus finmarchicus. General and Comparative Endocrinology. 156, 454-459 (2008) [PubMed: 18413275]

53. Li LJ, Kelley WP, Billimoria CP, Christie AE, Pulver SR, Sweedler JV, Marder E: Mass spectrometric investigation of the neuropeptide complement and release in the pericardial organs of the crab, Cancer borealis. Journal of Neurochemistry. 87, 642-656 (2003) [PubMed: 14535947]

54. Ma M, Wang J, Chen R, Li L: Expanding the Crustacean neuropeptidome using a multifaceted mass spectrometric approach. J Proteome Res. 8, 2426-2437 (2009) [PubMed: 19222238] 


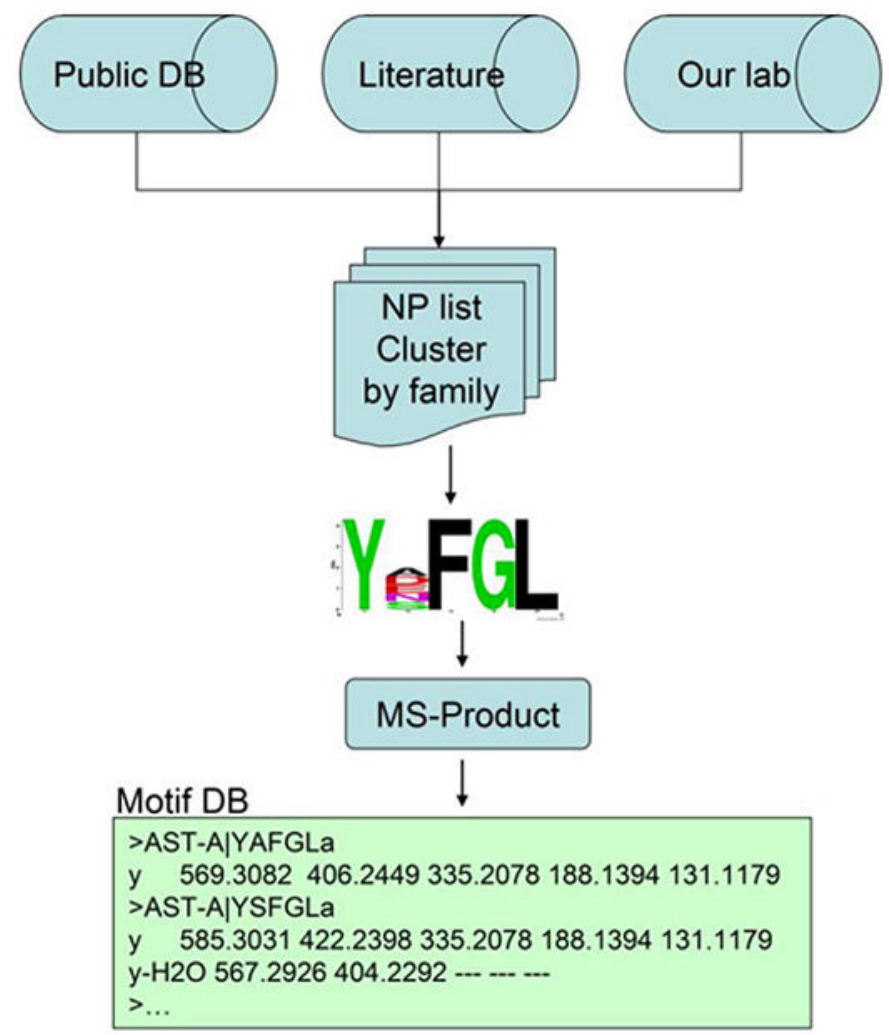

Figure 1.

The diagram illustrates the construction of a motif database. Three resources including public databases (e.g. NCBI), previous publications and the neuropeptide discoveries by our lab are used to generate a collection of crustacean neuropeptides which are clustered into families according to their conserved motifs. Then each family of neuropeptides are aligned with WebLogo (version 3.0, http://weblogo.threeplusone.com/) to extract detailed motifs followed by in silico fragmentation of these extracted motifs with MS-product (http:// prospector.ucsf.edu/prospector/cgi-bin/msform.cgi?form=msproduct). Finally, the motif and the corresponding $b$ - or $y$ - series fragments are compiled into a motif database. 
ETH, 1

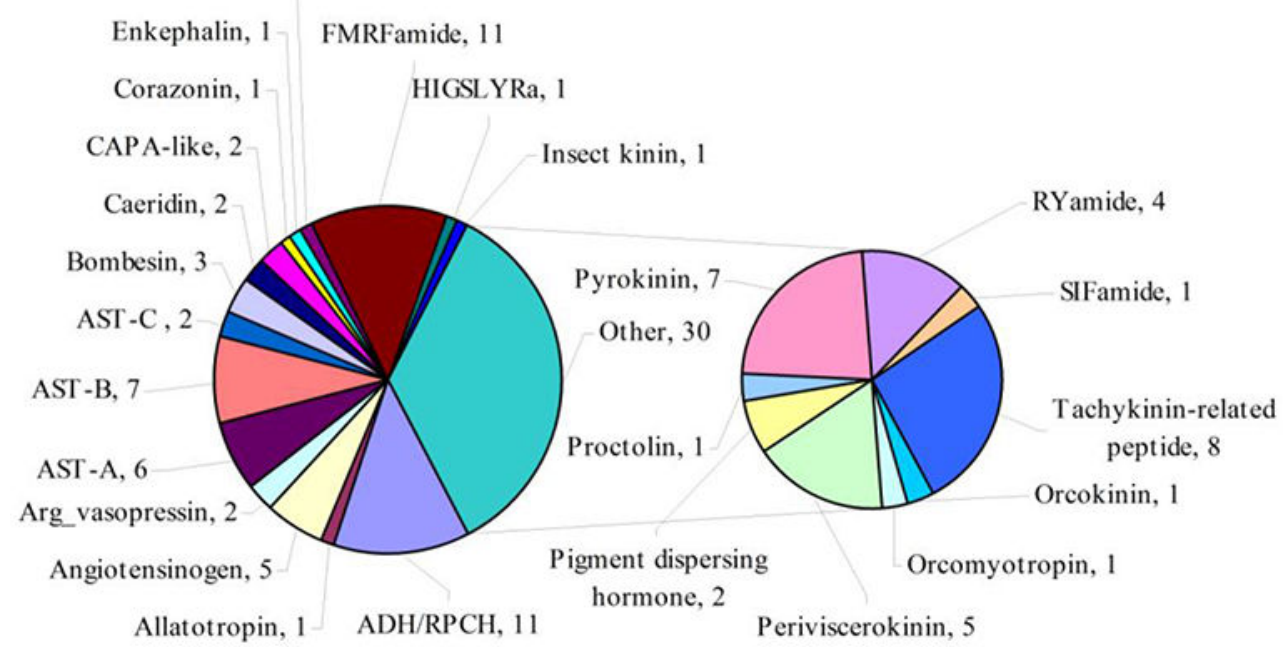

Figure 2.

The distribution of motifs according to their families. The number represents the total number of motifs associated with each family. 


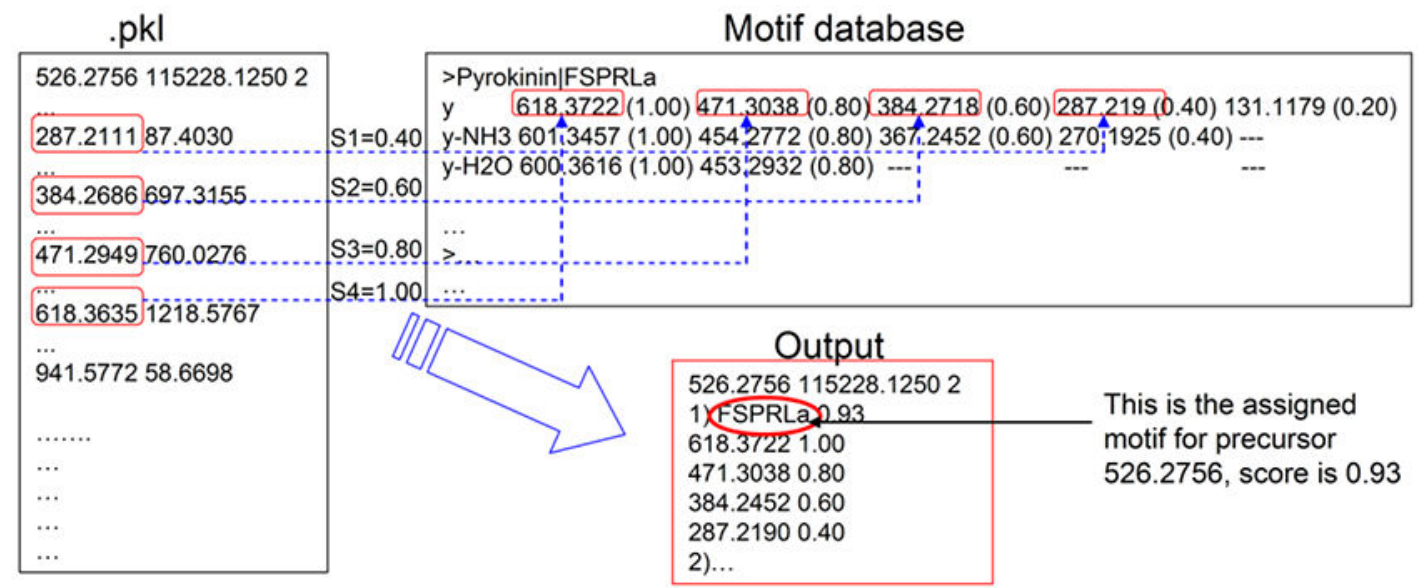

Figure 3.

The schematic representation of motif assignment. The experimental fragments associated with the precursor (in .pkl file) are searched against a predefined motif database in which each motif contains y-series ions $\left(\mathrm{y}, \mathrm{y}-\mathrm{NH}_{3}, \mathrm{y}-\mathrm{H}_{2} \mathrm{O}\right)$ or b-series ions $\left(\mathrm{b}, \mathrm{b}-\mathrm{NH}_{3},-\mathrm{H}_{2} \mathrm{O}\right)$. The scores from the matched experimental and theoretical fragments (S1, S2, S3, S4) are used to calculate the overall score for motif assignment as shown in Output file. The motif with the highest score is assigned to the precursor. 

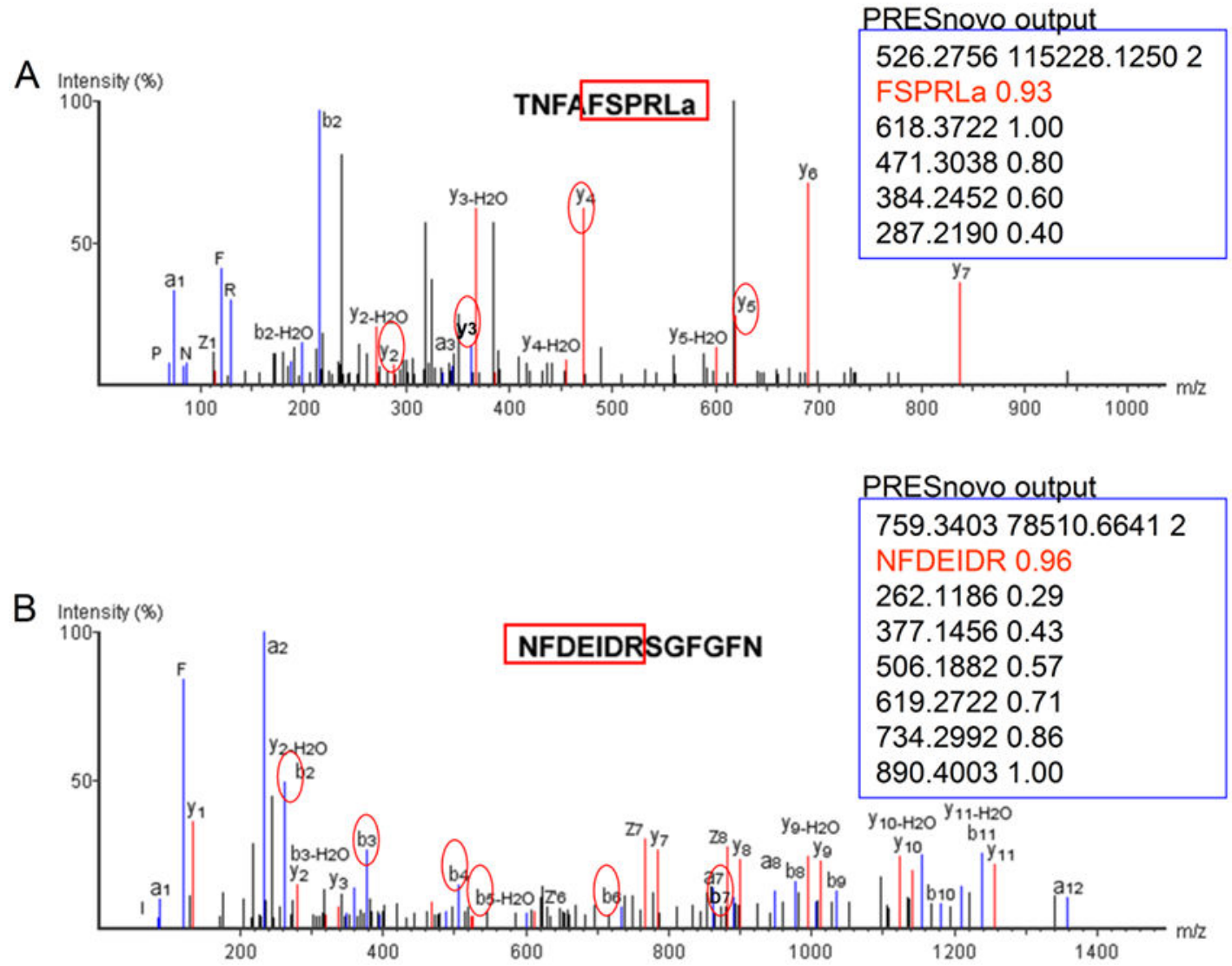

Figure 4.

The representative tandem MS spectra and PRESnovo output. A) MS/MS spectrum of TNFAFSPRLa. PRESnovo found four motif-associated fragments (y2, y3, y4 and y5) and then assigned C-terminal motif of FSPRLa to this precursor; B) MS/MS spectrum of NFDEIDRSGFGFN. PRESnovo found six motif-associated fragments (b2, b3, b4, b5, b6 and b7) and then assigned N-terminal motif of NFDEIDR to this precursor. 
A Intensity (\%)

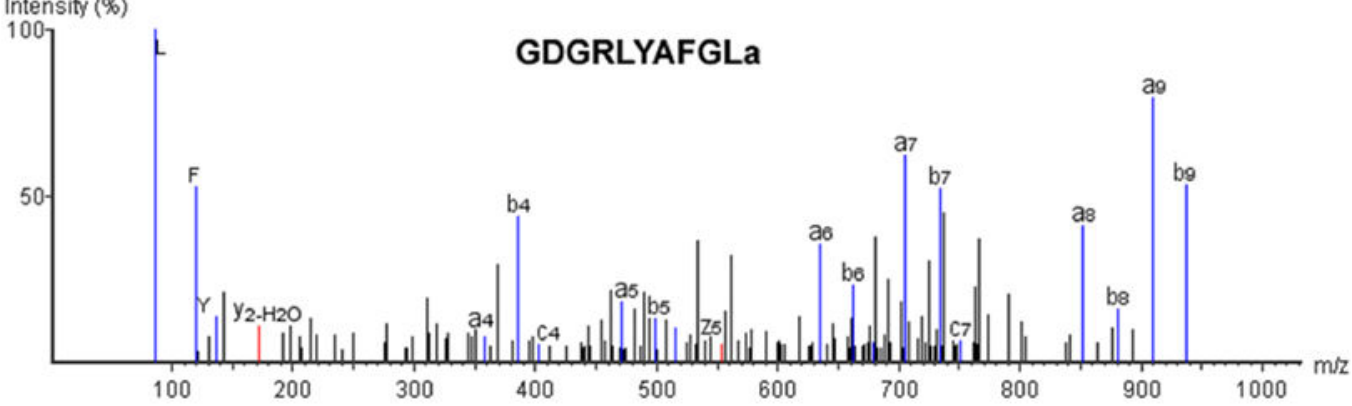

B

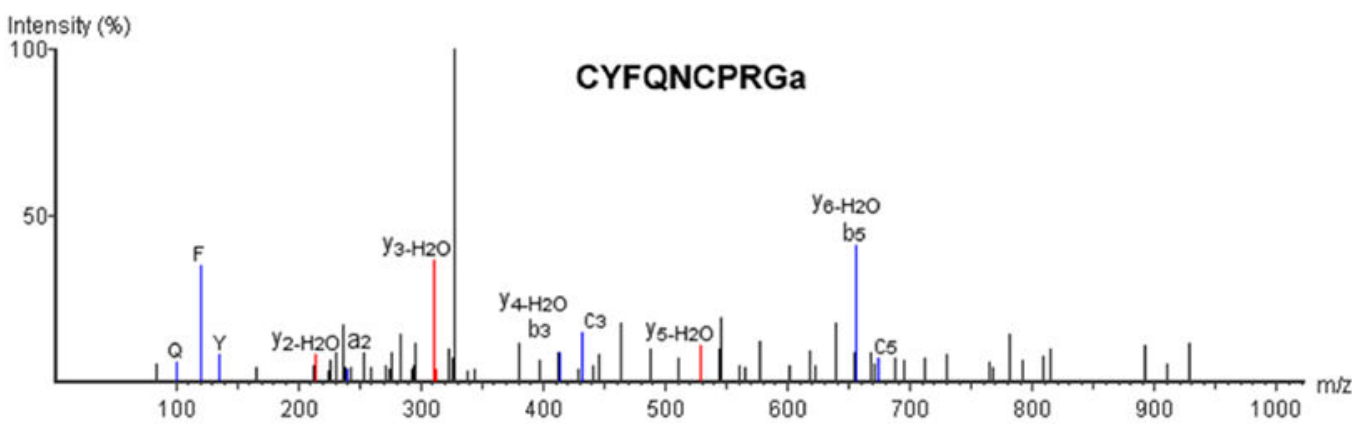

Figure 5.

PRESnovo fails to interpret tandem MS spectra of AST-A peptide and disulfide bond bridging peptide. A) a/b/c ions dominate in MS/MS spectrum of GDGRLYAFGLa; B) incomplete motif-associated fragments in MS/MS spectrum of CYFQNCPRGa. 

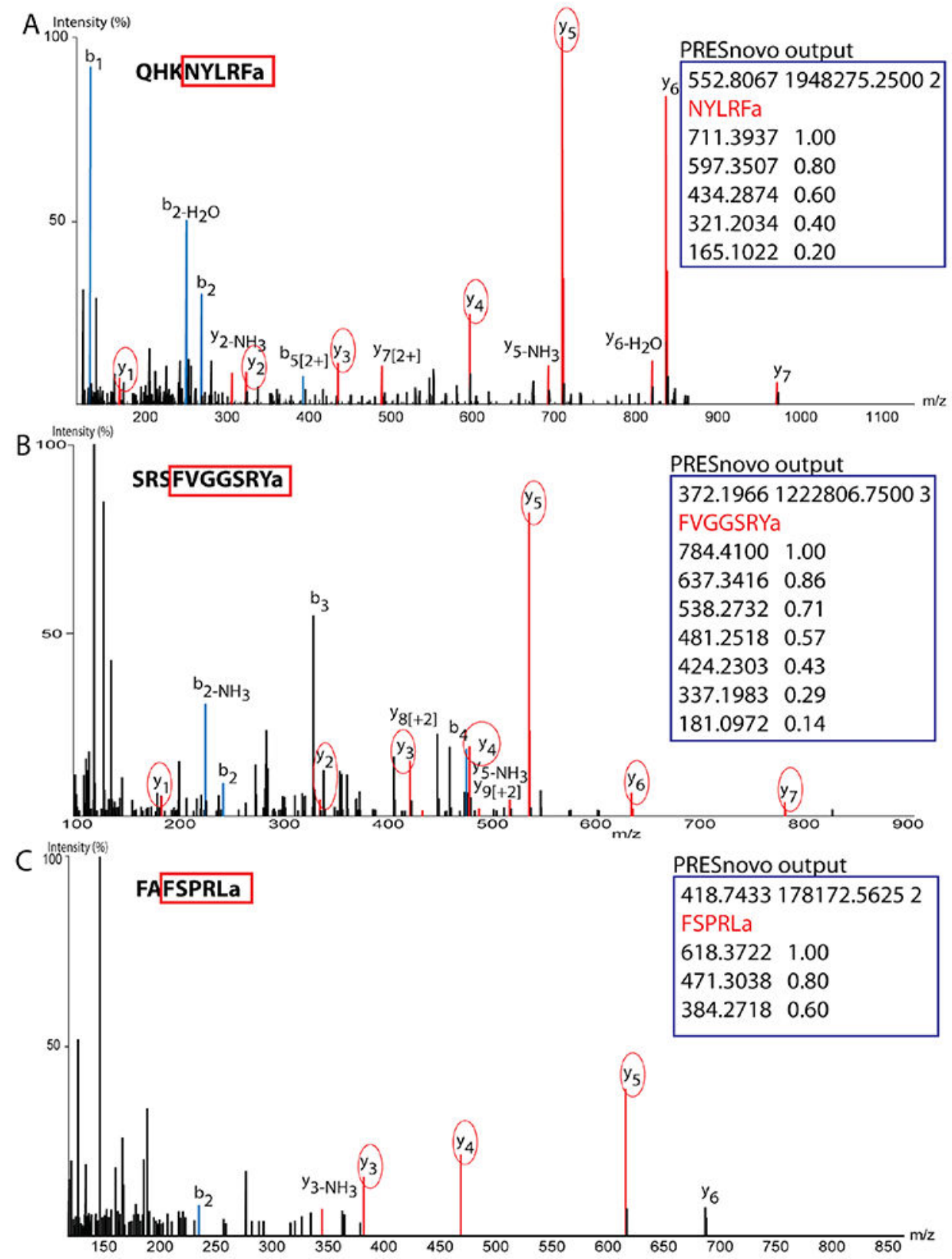

Figure 6.

MS/MS spectra of putative novel neuropeptides detected in (A) brain and (B) sinus gland of Jonah crab, $C$. borealis, as well as a neuropeptide matching the crustacean neuropeptide database that PEAKS failed to assign correctly. In all 3 cases, PRESnovo was able to identify fragment ions indicative of common motifs. 
Table 1.

The identified peptide standards by PRESnovo and PEAKS 7, with the displayed sequence being the output from each software that most closely matches the correct sequence.

\begin{tabular}{lllll}
\hline Family & Mass & Real Sequence & $\begin{array}{l}\text { PRESnovo } \\
\text { (Motif) }\end{array}$ & PEAKS 7 \\
\hline CCAP & 955.37 & PFCNAFTGCa & FIRFa & MCSAAGACAAT \\
RYamide & 975.44 & SGFYANRYa & FYANRYa & GRNTAAGGGDT \\
Pyrokinin & 1036.53 & SGGFAFSPRLa & FSPRLa & SGGFAFM(O)AFFFGT \\
Pyrokinin & 1050.55 & TNFAFSPRLa & FSPRLa & GS $\underline{\text { FAFSPVGIa }}$ \\
AST-A & 1066.54 & GDGRLYAFGLa & FGPRLa & TGGAQPEQLPAa \\
AVP & 1083.44 & CYFQNCPRGa & NSELINSILG & M(O)SQEPAAHM(O) $\underline{\text { Ga }}$ \\
FLP & 1104.57 & GAHKNYLRF & NYLRFa & HQGAGGVPMRPa \\
AST-B & 1106.50 & QWSSMRGAWa & WSSMRGAWa & TGRSSGAAAGADS \\
AST-B & 1259.64 & SGKWSNLRGAWa & WSNLRGAWa & QCARSVAGGSASAPa \\
Angiotension & 1281.65 & DRVYVHPFHL & DRVYVHPF & SAGPVEGGDLMLH \\
AST-A & 1334.70 & APSGAQRLYGFGLa & pQVNFSPNWa & APSGATCSSMGVGVLa \\
AST-B & 1469.68 & VPNDWAHFRGSWa & WAHFRGSWa & VMDLGSAGSGNGMQM(O) \\
Orcokinin & 1472.66 & NFDEIDRSGFGFAa & NFDEIDR & $\underline{\text { NFDELDAGSGSGGT }}$ \\
Orcokinin & 1473.64 & NFDEIDRSGFGFA & NFDEIDR & CTGDELDAGPGGAPGGT \\
Orcokinin & 1516.65 & NFDEIDRSGFGFN & NFDEIDR & GCTDENNNM(O)EGGCGT \\
\hline * & & & & \\
the bold font type refers to the correct identifications. & & \\
a: amide. The underlined residues are the correctly identified by PEAKS 7. 11 were identified by PRESnovo while 1 by PEAKS 7 \\
(NFDEIDRSGFGFAa, based on criteria of six consecutively correct residues)
\end{tabular}

J Am Soc Mass Spectrom. Author manuscript; available in PMC 2020 July 03. 
Table 2.

Identified neuropeptides in brain tissue of green crab, $C$. maenas

\begin{tabular}{|c|c|c|}
\hline Family & Mass & Sequence \\
\hline AST-A & 768.38 & EAYAGFLa \\
\hline AST-A & 779.39 & NPYAFGLa \\
\hline AST-A & 779.39 & GGPYAFGLa \\
\hline AST-A & 780.38 & DPYAFGLa \\
\hline AST-A & 793.41 & AGPYAFGLa \\
\hline AST-A & 794.39 & EPYAFGLa \\
\hline AST-A & 807.43 & AAPYAFGLa \\
\hline AST-A & 809.40 & AGPYSFGLa \\
\hline AST-A & 823.42 & ASPYAFGLa \\
\hline AST-A & 850.47 & GKPYAFGLa \\
\hline AST-A & 852.40 & EPYEFGLa \\
\hline AST-A & 878.47 & RGPYAFGLa \\
\hline AST-A & 896.44 & FSGASPYGLa \\
\hline AST-A & 908.48 & ARPYSFGLa \\
\hline AST-A & 924.50 & LKAYDFGLa \\
\hline AST-A & 925.46 & ATGQYAFGLa \\
\hline AST-A & 938.49 & TRPYSFGLa \\
\hline AST-A & 922.52 & KLPYSFGLa \\
\hline AST-B & 1106.57 & QWSSMRGAWa \\
\hline AST-B & 1259.70 & SGKWSNLRGAWa \\
\hline AST-B & 1292.62 & STNWSSLRSAWa \\
\hline AST-B & 1469.69 & VPNDWAHFRGSWa \\
\hline CCAP & 956.38 & PFCNAFTGCa \\
\hline FaRPs & 734.40 & GPFLRFa \\
\hline FaRPs & 850.49 & RNFLRFa \\
\hline FaRPs & 886.55 & PSLRLRFa \\
\hline FaRPs & 904.50 & PSMRLRFa \\
\hline FaRPs & 920.50 & $\operatorname{PSM}(\mathrm{O}) \mathrm{RLRFa}$ \\
\hline FaRPs & 937.52 & NRSFLRFa \\
\hline FaRPs & 953.52 & SRNYLRFa \\
\hline FaRPs & 964.53 & NRNFLRFa \\
\hline FaRPs & 965.52 & DRNFLRFa \\
\hline FaRPs & 976.51 & PQGNFLRFa \\
\hline FaRPs & 1021.55 & GNRNFLRFa \\
\hline FaRPs & 1022.53 & GDRNFLRFa \\
\hline FaRPs & 1047.56 & APQGNFLRFa \\
\hline FaRPs & 1103.60 & GAHKNFLRFa \\
\hline FaRPs & 1104.62 & SMPSLRLRFa \\
\hline FaRPs & 1123.62 & GLSRNYLRFa \\
\hline
\end{tabular}

J Am Soc Mass Spectrom. Author manuscript; available in PMC 2020 July 03. 


\begin{tabular}{|c|c|c|c|}
\hline & & & \\
\hline & Family & Mass & Sequence \\
\hline & FaRPs & 1136.58 & DGNRNFLRFa \\
\hline \multirow{7}{*}{ 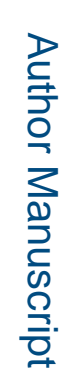 } & FaRPs & 1157.61 & YGNRSFLRFa \\
\hline & FaRPs & 1207.62 & DQNRNFLRFa \\
\hline & FaRPs & 1270.64 & pQDLDHVFLRFa \\
\hline & FaRPs & 1270.67 & PELDHVFLRFa \\
\hline & FaRPs & 1287.67 & QDLDHVFLRFa \\
\hline & FaRPs & 1288.62 & QDNDHVFLRFa \\
\hline & FaRPs & 1313.77 & DARTAPLRLRFa \\
\hline & Orcokinin & 936.42 & DEIDRSGFa \\
\hline & Orcokinin & 1197.54 & NFDEIDRSGFa \\
\hline & Orcokinin & 1227.55 & NFDEIDRSSFa \\
\hline & Orcokinin & 1255.54 & NFDEIDRSGFG \\
\hline & Orcokinin & 1269.55 & NFDEIDRSGFA \\
\hline$\geq$ & Orcokinin & 1285.55 & NFDEIDRSSFG \\
\hline 穴 & Orcokinin & 1299.57 & NFDEIDRSSFA \\
\hline 든 & Orcokinin & 1473.65 & NFDEIDRSGFGFA \\
\hline ఏ) & Orcokinin & 1546.67 & NFDEIDRSSFGFN \\
\hline$\frac{\sqrt{2}}{\mathrm{c}}$ & Orcomyotropin & 1185.51 & FDAFTTGFGHS \\
\hline$\underline{\underline{\rho}}$ & Others & 843.47 & HIGSLYRa \\
\hline 후 & Others & 915.53 & KIFEPLVA \\
\hline & Others & 1371.78 & KIFEPLRDKNL \\
\hline & PDH & 1926.01 & NSELINSLLGIPKVMNDAa \\
\hline & Pyrokinin & 877.51 & LYFAPRLa \\
\hline & Pyrokinin & 1023.55 & TSFAFSPRLa \\
\hline & Pyrokinin & 1108.56 & TDGFAFSPRLa \\
\hline$\unrhd$ & $\mathrm{RPCH}$ & 929.43 & pQLNFSPGWa \\
\hline $\overrightarrow{\bar{\tau}}$ & SIFamide & 1160.64 & RKPPFNGSIFa \\
\hline 7 & SIFamide & 1380.73 & GYRKPPFNGSIFa \\
\hline बा & Tachykinin & 765.39 & SGFLGMRa \\
\hline$\stackrel{\beth}{\complement}$ & Tachykinin & 862.45 & PSGFLGMRa \\
\hline ก) & Tachykinin & 878.44 & PSGFLGM(O)Ra \\
\hline ర். & Tachykinin & 933.48 & APSGFLGMRa \\
\hline & Tachykinin & 934.46 & APSGFLGMR \\
\hline & Tachykinin & 949.48 & APSGFLGM(O)Ra \\
\hline & Tachykinin & 963.49 & TPSGFLGMRa \\
\hline & Tachykinin & 979.49 & TPSGFLGM(O)Ra \\
\hline & Tachykinin & 991.49 & APSGFLGMRG \\
\hline$\unrhd$ & Tachykinin & 1007.48 & APSGFLGM(O)RG \\
\hline 㝘 & * Red color repr & ts novel 1 & uropeptides identified in greer \\
\hline & & 11 amt & tion. "p" indicates pyroglutama \\
\hline
\end{tabular}

J Am Soc Mass Spectrom. Author manuscript; available in PMC 2020 July 03. 
Table 3.

Identified neuropeptides matching to the database in brain and sinus gland tissue of Jonah crab, C. borealis

\begin{tabular}{lrll}
\hline Family & \multicolumn{1}{c}{ Mass } & Sequence & Tissue \\
\hline AST-B & 1106.5081 & AGWSSMRGAWa & Brain, SG \\
AST-B & 1106.5081 & QWSSMRGAWa & Brain, SG \\
AST-B & 1292.6262 & STNWSSLRSAWa & Brain, SG \\
Corazonin & 1368.6211 & pQTFQYSRGWTNa & Brain \\
FaRP & 1146.6411 & APQRNFLRFa & SG \\
FaRP & 965.5195 & DRNFLRFa & Brain, SG \\
FaRP & 961.5246 & ERNFLRFa & Brain \\
FaRP & 1103.5989 & GAHKNYLRFa & SG \\
FaRP & 1021.5569 & GNRNFLRFa & Brain, SG \\
FaRP & 1145.5981 & GYSKNYLRFa & Brain, SG \\
FaRP & 816.4758 & HVFLRFa & Brain \\
FaRP & 1103.6353 & KHKNYLRFa & Brain \\
FaRP & 694.3915 & NFLRFa & Brain, SG \\
FaRP & 964.5355 & NRNFLRFa & Brain, SG \\
FaRP & 1270.6458 & pQDLDHVFLRFa & Brain, SG \\
FaRP & 1287.6724 & QDLDHVFLRFa & Brain, SG \\
FaRP & 850.4926 & RNFLRFa & Brain \\
FaRP & 1180.6101 & SENRNFLRFa & Brain, SG \\
Proctolin & 648.3595 & RYLPT & SG \\
Pyrokinin & 835.4704 & FAFSPRLa & Brain \\
Pyrokinin & 877.5174 & LYFAPRLa & Brain, SG \\
Pyrokinin & 1036.5454 & SGGFAFSPRLa & SG \\
Pyrokinin & 1050.561 & TNFAFSPRLa & Brain \\
Ryamide & 1029.4668 & EGFYSQRYa & SG \\
RYamide & 783.4028 & FVGGSRYa & SG \\
RYamide & 861.4133 & FYSQRYa & SG \\
RYamide & 1113.5679 & RSSFVGGSRYa & SG \\
RYamide & 975.4562 & SGFYANRYa & Brain, SG \\
Ryamide & 1113.5679 & SSRFVGGSRYa & SG \\
\hline Tachyinin & 933.4854 & APSGFLGMRa & Brain, SG \\
Fanina & TPSGFLGMRa & Brain, SG \\
\hline
\end{tabular}

“a” represents C-terminal amidation. "p" means pyroglutamate Gln or Glu. "SG" indicates sinus gland. 
Table 4.

Identified putative novel neuropeptides in the brain and sinus gland tissue of Jonah crab, C. borealis

\begin{tabular}{|c|c|c|c|}
\hline Family & Mass & Sequence & Tissue \\
\hline AST-A & 1065.55 & APTDLYAFGLa & Brain \\
\hline AST-A & 1065.55 & PATDLYAFGLa & Brain \\
\hline AST-A & 983.4824 & QRDYSFGLa & Brain \\
\hline AST-A & 939.4926 & RQAYSFGLa & SG \\
\hline AST-B & 1259.652 & KGSWSNLRGAWa & Brain \\
\hline AST-B & 1292.608 & MGNWSSLRSAWa & Brain \\
\hline FaRP & 964.5242 & AAQNFLRFa & SG \\
\hline FaRP & 1103.599 & AGHKNYLRFa & SG \\
\hline FaRP & 1146.641 & APAGRNFLRFa & Brain \\
\hline FaRP & 1146.641 & APGARNFLRFa & Brain, SG \\
\hline FaRP & 1146.641 & APGRANFLRFa & Brain, SG \\
\hline FaRP & 1006.535 & APGSNFLRFa & Brain \\
\hline FaRP & 976.5242 & APNNFLRFa & Brain \\
\hline FaRP & 1267.624 & CAENRNFLRFa & Brain \\
\hline FaRP & 1267.607 & CCPGGRNFLRFa & Brain \\
\hline FaRP & 1267.607 & CCPNRNFLRFa & Brain \\
\hline FaRP & 1324.646 & DGMGNRNFLRFa & Brain \\
\hline FaRP & 1270.639 & DHVCHVFLRFa & SG \\
\hline FaRP & 1394.567 & DSGPDDYGHMRFa & SG \\
\hline FaRP & 1394.567 & DSPGDDYGHMRFa & Brain \\
\hline FaRP & 1180.61 & DTNRNFLRFa & SG \\
\hline FaRP & 1394.567 & pEGTSDDYGHMRFa & SG \\
\hline FaRP & 1267.624 & EACNRNFLRFa & Brain \\
\hline FaRP & 1222.621 & EERNNFLRFa & Brain \\
\hline FaRP & 1532.762 & EESAEVPPNFLRFa & Brain \\
\hline FaRP & 1022.53 & EGAANFLRFa & Brain \\
\hline FaRP & 1233.589 & EQANDNFLRFa & Brain \\
\hline FaRP & 1769.896 & EQQPHAGLSAGNFLRFa & Brain \\
\hline FaRP & 1180.61 & ESNRNFLRFa & SG \\
\hline FaRP & 1180.61 & ESRNNFLRFa & Brain, SG \\
\hline FaRP & 1324.664 & ESSNGRNFLRFa & Brain \\
\hline FaRP & 1032.598 & FALAGRPRFa & Brain \\
\hline FaRP & 1180.614 & FGAPNNFLRFa & Brain \\
\hline FaRP & 1103.599 & HAGKNYLRFa & Brain, SG \\
\hline FaRP & 1270.639 & HDVCHVFLRFa & Brain \\
\hline FaRP & 1146.594 & HEVSNFLRFa & Brain \\
\hline FaRP & 1249.647 & HFDRNFLRFa & Brain \\
\hline FaRP & 1248.663 & HFNRNFLRFa & Brain \\
\hline FaRP & 1146.594 & HSDLNFLRFa & Brain \\
\hline
\end{tabular}

J Am Soc Mass Spectrom. Author manuscript; available in PMC 2020 July 03. 


\begin{tabular}{|c|c|c|c|}
\hline Family & Mass & Sequence & Tissue \\
\hline FaRP & 1532.832 & KAAPSNRNNFLRFa & Brain \\
\hline FaRP & 1146.666 & KAPRNFLRFa & SG \\
\hline FaRP & 1498.746 & KCSTDGRGNFLRFa & Brain \\
\hline FaRP & 1146.666 & KGAPVNFLRFa & SG \\
\hline FaRP & 966.5399 & KGSNFLRFa & Brain \\
\hline FaRP & 1103.599 & KHAGNYLRFa & SG \\
\hline FaRP & 1103.599 & KHQNYLRFa & SG \\
\hline FaRP & 1146.666 & KLPNNFLRFa & Brain \\
\hline FaRP & 1146.678 & KPARNFLRFa & SG \\
\hline FaRP & 1248.709 & KQQLGNFLRFa & Brain \\
\hline FaRP & 1146.678 & KRAPNFLRFa & SG \\
\hline FaRP & 1305.749 & KRMVPNFLRFa & Brain \\
\hline FaRP & 1145.598 & KSGYNYLRFa & Brain, SG \\
\hline FaRP & 1333.737 & KSPNGRNFLRFa & Brain \\
\hline FaRP & 1145.598 & KSYGNYLRFa & SG \\
\hline FaRP & 1146.666 & KVPQNFLRFa & SG \\
\hline FaRP & 1333.737 & LQAGNRNFLRFa & Brain \\
\hline FaRP & 1021.553 & MVPNFLRFa & Brain \\
\hline FaRP & 976.5242 & NPANFLRFa & Brain \\
\hline FaRP & 992.5192 & NSPNFLRFa & Brain \\
\hline FaRP & 1544.748 & NSYSERNNFLRFa & Brain \\
\hline FaRP & 1146.641 & PAGARNFLRFa & SG \\
\hline FaRP & 976.5242 & PAGGNFLRFa & Brain \\
\hline FaRP & 1006.535 & PNTNFLRFa & Brain \\
\hline FaRP & 1146.605 & pQGQRNFLRFa & SG \\
\hline FaRP & 1222.625 & pQQAAFNFLRFa & Brain \\
\hline FaRP & 1551.78 & PVMEMRNNFLRFa & Brain \\
\hline FaRP & 1103.599 & QHKNYLRFa & Brain, SG \\
\hline FaRP & 1180.599 & QKDDNFLRFa & Brain \\
\hline FaRP & 1333.737 & QLAGNRNFLRFa & Brain \\
\hline FaRP & 1146.641 & QPARNFLRFa & SG \\
\hline FaRP & 1248.695 & QRNRNFLRFa & Brain \\
\hline FaRP & 1146.641 & RAGAPNFLRFa & SG \\
\hline FaRP & 965.5195 & RDNFLRFa & Brain, SG \\
\hline FaRP & 964.5355 & RGGNFLRFa & Brain, SG \\
\hline FaRP & 1021.557 & RGNNFLRFa & SG \\
\hline FaRP & 1180.61 & RNDTNFLRFa & Brain \\
\hline FaRP & 1180.61 & RNESNFLRFa & Brain, SG \\
\hline FaRP & 1021.557 & RNGNFLRFa & Brain, SG \\
\hline FaRP & 964.5355 & RNNFLRFa & Brain, SG \\
\hline FaRP & 1180.61 & RNSENFLRFa & SG \\
\hline FaRP & 3692.954 & RPGQLLLAEASSWLPTQQEGTKRGYSKNYLRFa & Brain \\
\hline
\end{tabular}

J Am Soc Mass Spectrom. Author manuscript; available in PMC 2020 July 03. 


\begin{tabular}{|c|c|c|c|}
\hline Family & Mass & Sequence & Tissue \\
\hline FaRP & 1248.695 & RQNRNFLRFa & Brain \\
\hline FaRP & 1276.679 & SAGPNRNFLRFa & Brain \\
\hline FaRP & 1219.658 & SAPNRNFLRFa & Brain \\
\hline FaRP & 1394.567 & SDGPDDYGHMRFa & Brain \\
\hline FaRP & 1180.61 & SERNNFLRFa & SG \\
\hline FaRP & 1483.71 & STDEPYPNFLRFa & Brain \\
\hline FaRP & 1180.599 & STPNSNFLRFa & SG \\
\hline FaRP & 1180.61 & TDRNNFLRFa & SG \\
\hline FaRP & 1180.635 & TSAQVNFLRFa & SG \\
\hline FaRP & 1544.729 & TSDELTTCNFLRFa & Brain \\
\hline FaRP & 1180.599 & TSPNSNFLRFa & SG \\
\hline FaRP & 1180.599 & TSSNPNFLRFa & SG \\
\hline FaRP & 1532.836 & VPGFAPNRNFLRFa & Brain \\
\hline FaRP & 1004.523 & YFNFLRFa & Brain \\
\hline FaRP & 1145.598 & YGSKNYLRFa & SG \\
\hline Pyrokinin & 2380.269 & FNGPKPLAKYVDTNFAFSPRLa & Brain \\
\hline Pyrokinin & 2379.252 & FNPGKLPKSQMTTNFAFSPRLa & Brain \\
\hline Pyrokinin & 1036.545 & GSGFAFSPRLa & Brain \\
\hline Pyrokinin & 1050.561 & QSFAFSPRLa & Brain, SG \\
\hline RYamide & 1029.467 & pEGFYSQRYa & SG \\
\hline RYamide & 975.4562 & GSFYANRYa & Brain, SG \\
\hline RYamide & 1029.467 & pQGFYSQRYa & Brain \\
\hline RYamide & 2133.035 & SADRTQLTERSGFYANRYa & Brain \\
\hline RYamide & 1113.568 & SRSFVGGSRYa & SG \\
\hline RYamide & 2133.035 & TGARDGTLTERSGFYANRYa & Brain \\
\hline $\begin{array}{l}\text { Tachykin } \\
\text { in }\end{array}$ & 1143.622 & APPLSGFLGMRa & SG \\
\hline $\begin{array}{l}\text { Tachykin } \\
\text { in }\end{array}$ & 1175.623 & KNAPSGFLGMRa & Brain \\
\hline $\begin{array}{l}\text { Tachykin } \\
\text { in }\end{array}$ & 1145.613 & KSAHTFLGMRa & SG \\
\hline $\begin{array}{l}\text { Tachykin } \\
\text { in }\end{array}$ & 1145.576 & KSDHGFLGMRa & SG \\
\hline $\begin{array}{l}\text { Tachykin } \\
\text { in }\end{array}$ & 1253.547 & NCCAPSGFLGMRa & Brain \\
\hline
\end{tabular}

"a" represents C-terminal amidation. "p" means pyroglutamate Gln or Glu. "SG" indicates sinus gland. 